\title{
SENSITIVITY AND STATISTICAL ANALYSIS WITHIN THE ELABORATION OF STEEL PLATED GIRDER RESISTANCE
}

\author{
J. Melcher ${ }^{1}{ }^{*}$, M Škaloud ${ }^{2}$, Z. Kala ${ }^{1}$, M. Karmazínová ${ }^{1}$ \\ ${ }^{1}$ Brno University of Technology, CZ-602 00 Brno, Czech Republic, \\ ${ }^{2}$ Professor, Academy of Sciences of the Czech republic, Prague \\ *(Corresponding author: E-mail: melcher.j@fce.vutbr.cz)
}

\begin{abstract}
The objective of the paper is to analyse the influence of initial imperfections on the behaviour of thin-walled girders welded of slender plate elements. The girder was modelled, using the geometrically and materially non-linear variant of the shell finite element method, by the ANSYS program. The ultimate static load-carrying capacity and the state of stress were considered as the output analysed quantities. The influence of the variability of initial imperfections on the variability of ultimate static load-carrying capacity and on the variability of the state of stress studied was calculated by sensitivity analysis. The sensitivity analysis was evaluated on a computer by applying the numerical simulation LHS method and statistical characteristics evaluated, based on the experiments. Real tests of girders with random initial imperfections the occurrence frequency of which is equivalent to experimental results are simulated numerically. In each LHS method run, both load-carrying capacity and state of stress are evaluated on the model based on nonlinear variant of shell finite elements. The stress state was evaluated by bending stresses developing in the crack-prone areas of a web "breathing" under repeated loads, which - as it was demonstrated by the experiments - occurred at the toes of the fillet welds connecting the "breathing" web with the girder flanges and stiffeners.
\end{abstract}

Keywords: Steel structures, fatigue, imperfection, sensitivity, reliability, plated girder

\section{INTRODUCTION}

Thin-walled structures, i.e. systems made of slender plate elements are nowadays very frequently encountered in both building and bridge construction. Among their most frequently used types are steel plate girders having a slender web, such as the girder shown in Figure 1.

The behaviour of steel girders is substantially affected by the buckling of the girder web, which for the kind of loading considered, is characterized by a diagonal buckled pattern the width and inclination of which depend on the rigidity of the peripheral elements of the web, i.e. of the flanges and stiffeners.

When the loading is quasi-constant, the failure mechanism consists of a diagonal plastic band in the web sheet and a system of more or less developed plastic areas in its boundary elements.

When the loading is repeated in a great number of cycles, then the web buckling is many times repeated, this phenomenon being now usually termed "web breathing". In this case the failure mechanism (Figure 2) is made more complex by the initiation and propagation of fatigue cracks occurring at the toes of the fillet welds that connect the breathing web with its peripheral elements. The experiments and the theoretical analysis have demonstrated that this phenomenon is influenced by a number of factors, among them a significant role being played by unavoidable initial imperfections (Kala [1]). As it is in their nature that the initial imperfections are random variables, stochastic sensitivity analysis seems to be an ideal tool for an analysis of their effect (Kala [2-3]). 


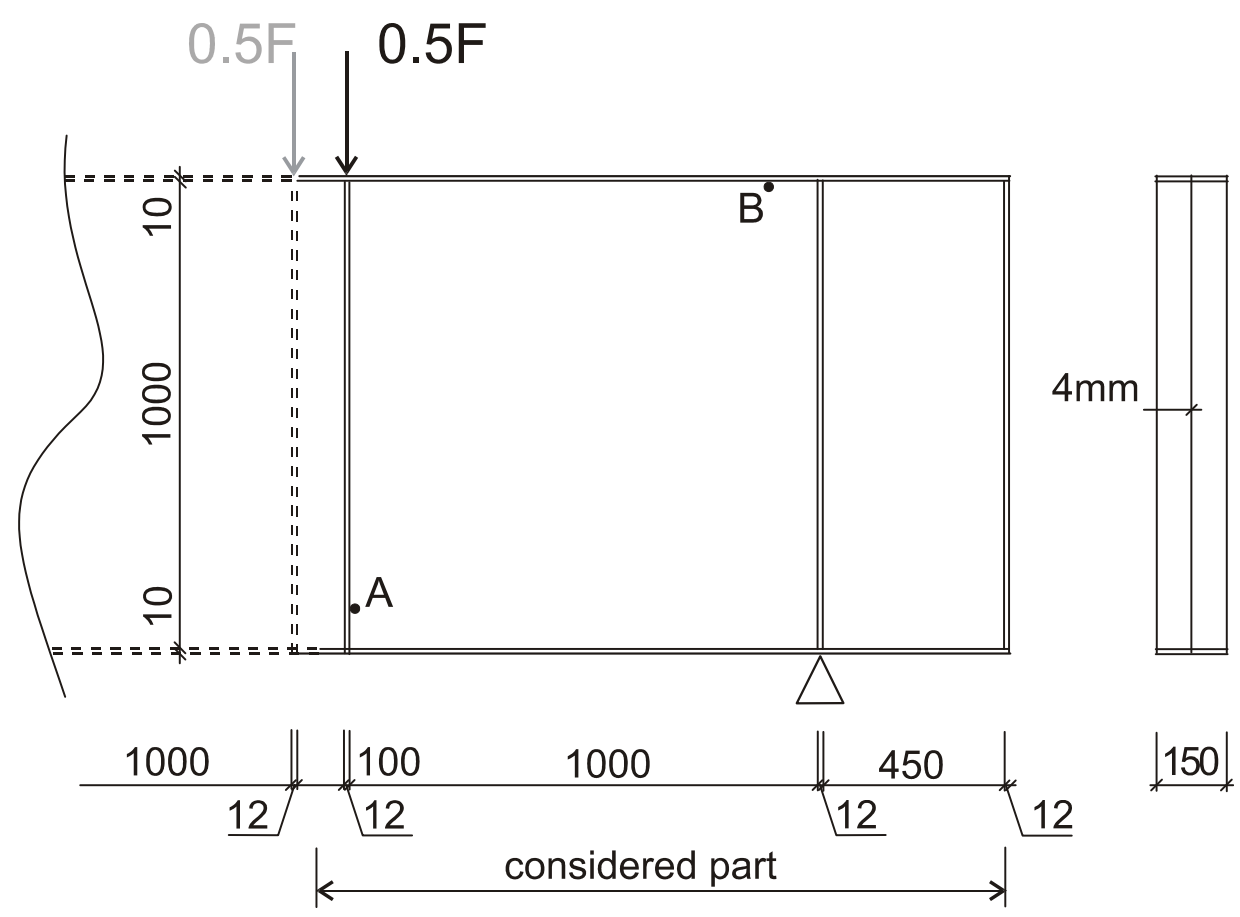

Figure 1. Geometry of the Tested Girder

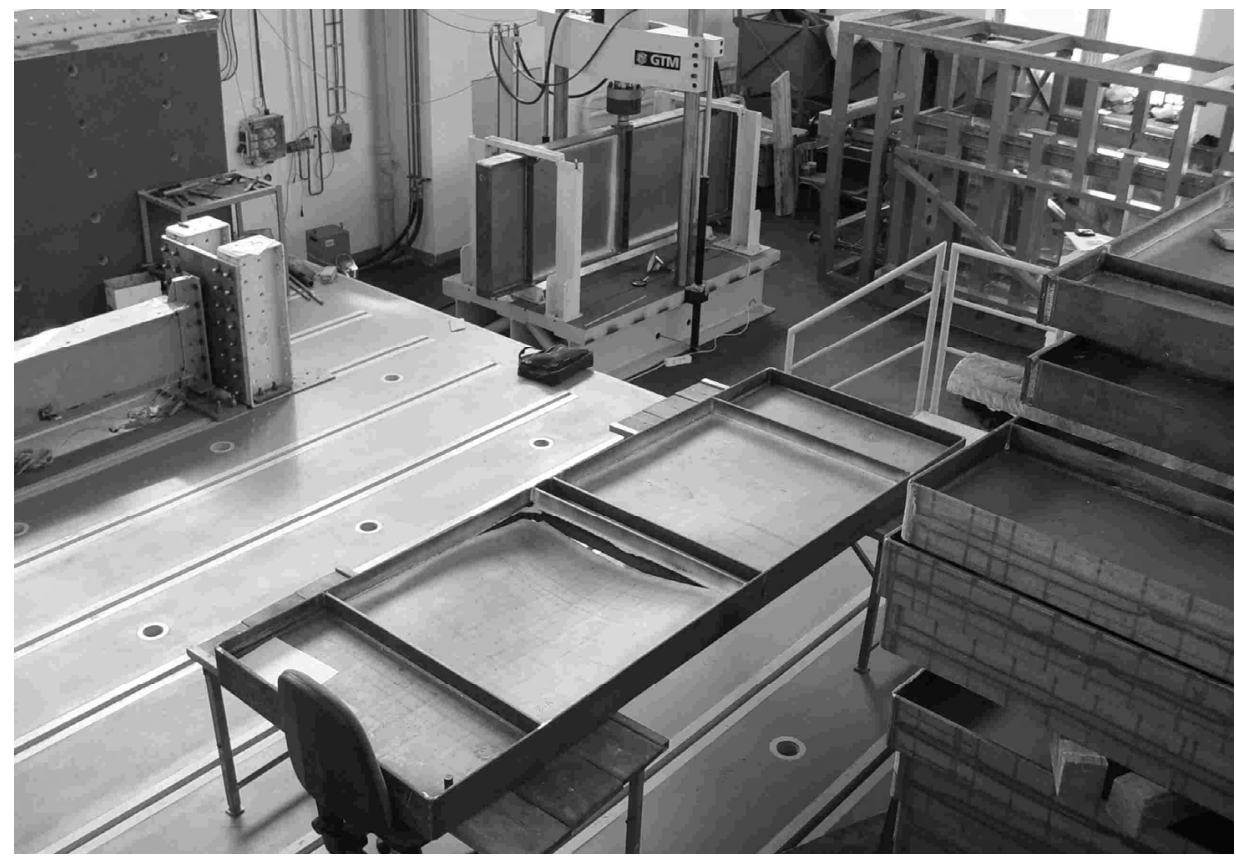

Figure 2. Test Specimen After Failure

\section{SENSITIVITY ANALYSIS METHODS}

The objective of this paper is therefore a stochastic sensitivity analysis which provides more extended information about the problem studied. The random input quantities are considered as if they were obtained by measurements, this enabling us to get quantified information about the influence of the scatter of individual parameters involved. This procedure can be employed with advantage in connection with the numerical simulation method Latin Hypercube Sampling Method (LHS), such as suggested in the review paper (Novák [4-5]) where also other variants of the 
stochastic sensitivity analysis are described. The LHS method makes it possible to simulate the realizations of input random quantities as if they were obtained by measurements.

A comprehensive review of various sensitivity analysis methods is given in (Saltelli [6]). For our research, the methods which can be applied for the sensitivity analysis evaluation can be divided as follows:

a) The methods based on the correlation coefficient study (Kala [2] and [7]).

b) The methods based on the study of variability coefficient ratios (Novák [4] and Kala [2]).

c) The methods based on the study of variances coefficient ratios (Kala [3] and [8]).

d) Special methods and methods for the probability analysis (Mang [9] and Juozapaitis [10]).

The first method can be applied practically to all numerical simulation methods of the Monte Carlo type. The method described is based on the assumption that there will be higher correlation degree with the output in case of the quantities relatively more sensitive to the output.

The so-called Spearman rank-order correlation $r_{\mathrm{i}}$ is frequently applied within the framework of a simulation method (Kala [2]). The Spearman rank-order correlation can be defined as:

$r_{i}=1-\frac{6 \sum_{j}\left(m_{j i}-n_{j}\right)^{2}}{N\left(N^{2}-1\right)} \quad r_{i} \in[-1,1]$

where $r_{\mathrm{i}}$ is the order representing the value of random variable $X_{\mathrm{i}}$ in an ordered sample among $N$ simulated values applied in the $j_{\text {th }}$ simulation (the order $m_{\mathrm{ji}}$ equals the permutation at LHS), $n_{\mathrm{j}}$ is the order of an ordered sample of the resulting variable for the $j_{\text {th }}$ run of the simulation process $\left(m_{\mathrm{ji}}-n_{\mathrm{j}}\right.$ is the difference between the ranks of two samples). If the coefficient $r_{\mathrm{i}}$ had the value near to 1 or -1 , it would suggest a very strong dependence of the output on the input. Opposite to this, the coefficient with its value near to zero will signalise a low influence.

The second method is based on the comparison of sensitivity coefficients $k_{\mathrm{i}}$, defined on behalf of variation coefficients by the relation:

$k_{i}=100 \frac{v_{y i}^{2}}{v_{y}^{2}}[\%]$

$v_{\mathrm{yi}}$ is the variation coefficient of the output quantity, assuming that all the input quantities except the $i_{\text {th }}$ one ( $i=1,2, \ldots, M$; where $M$ is number of input variables) are considered to be deterministic (during the simulation, they are equal to the mean value);

$v_{\mathrm{y}}$ is the variation coefficient of the output quantity, assuming that all the input quantities are considered to be random ones.

\section{INPUT RANDOM QUANTITIES}

Experimental research with statistical evaluation of results can serve as the basic information source of the statistical distribution of input random quantities (Melcher [11]). In the problem solved in our research, we started from the large experimental research of the material and geometrical characteristics of steel products made by a dominant Czech producer (Melcher [12]). 
A further random quantity which cannot be considered deterministically is Young's modulus $E$. The influence of the deviation of physical-mechanical material characteristics (of heterogeneousness above all) has been taken into consideration by the variability of this quantity. The Gaussian distribution with mean value $m_{\mathrm{E}}=210 \mathrm{GPa}$ and standard deviation $S_{\mathrm{E}}=12.6 \mathrm{GPa}$ was supposed (Soares [13] and Fukumoto [14]).

Table 1. Input Random Quantities

\begin{tabular}{clllll}
\hline No. & Name of random quantity & $\begin{array}{l}\text { Type of } \\
\text { distribution }\end{array}$ & Dimension & Mean & $\begin{array}{l}\text { Standard } \\
\text { deviation }\end{array}$ \\
\hline 1. & Amplitude of sine initial web curvature & Rectangular & $\mathrm{mm}$ & 0 & 2.887 \\
2. & Web thickness & Gauss & $\mathrm{mm}$ & 4 & 0.2 \\
3. & Web yield strength & Gauss & $\mathrm{MPa}$ & 284.5 & 21.5 \\
4. & Web Young's modulus & Gauss & $\mathrm{GPa}$ & 210 & 12.6 \\
5. & Thickness of upper flange & Gauss & $\mathrm{mm}$ & 10 & 0.7 \\
6. & Yield strength of upper flange & Gauss & $\mathrm{MPa}$ & 284.5 & 21.5 \\
7. & Young's modulus of upper flange & Gauss & $\mathrm{GPa}$ & 210 & 12.6 \\
8. & Thickness of lower flange & Gauss & $\mathrm{mm}$ & 10 & 0.7 \\
9. & Yield strength of lower flange & Gauss & $\mathrm{MPa}$ & 284.5 & 21.5 \\
10. & Young's modulus of lower flange & Gauss & $\mathrm{GPa}$ & 210 & 12.6 \\
11. & Thickness of left-hand stiffener & Gauss & $\mathrm{mm}$ & 12 & 0.84 \\
12. & Yield strength of left-hand stiffener & Gauss & $\mathrm{MPa}$ & 284.5 & 21.5 \\
13. & Young's modulus of left-hand stiffener & Gauss & $\mathrm{GPa}$ & 210 & 12.6 \\
14. & Thickness of central stiffener & Gauss & $\mathrm{mm}$ & 12 & 0.84 \\
15. & Yield strength of central stiffener & Gauss & $\mathrm{MPa}$ & 284.5 & 21.5 \\
16. & Young's modulus of central stiffener & Gauss & $\mathrm{GPa}$ & 210 & 12.6 \\
17. & Thickness of right-hand stiffener & Gauss & $\mathrm{mm}$ & 12 & 0.84 \\
18. & Yield strength of right-hand stiffener & Gauss & $\mathrm{MPa}$ & 284.5 & 21.5 \\
19. & Young's modulus of right-hand stiffener & Gauss & $\mathrm{GPa}$ & 210 & 12.6
\end{tabular}

The initial curvature of the web was introduced as one half-wave of the sine function both in the horizontal and vertical directions. The considered initial curvature variability is determined by the maximum amplitude value as a random quantity.

\section{STATISTICAL ANALYSIS}

The girder presented in Figure 1 was modelled by the finite element method, by applying the ANSYS program. The girder was modelled, in a very minute manner, by means of a mesh of shell four-nodes elements SHELL43. The girder symmetry and that of loading were made use of. For steel grade S235, bilinear cinematic material hardening was supposed. Further on, it was assumed that the onset of plastification occurred when the Mises stress exceeded the yield stress.

Within the framework of each run of the LHS method, the load-carrying capacity was found out by the geometrically and materially non-linear solution FEM. The Euler method based on proportional loading in combination with the Newton-Raphson method was used. The loading test is simulated by the incrementation of a loading step in the Euler method. The load-carrying capacity was determined as the loading rate at which the matrix of tangential toughness determinant $K_{\mathrm{t}}$ of the structure approaches zero with accurateness of $0.1 \%$. The incrementation run was decremented automatically. 200 "real tests" on girders according to Figure 1 with random imperfections were simulated by runs of the LHS method. 
Second part of the study was focused on analysing bending stresses which occur at the edges of the girder web and are perpendicular to these edges, and are generated by a load $=420 \mathrm{kN}$. This value of the load corresponds to $60 \%$ of the mean load - bearing capacity determined with used LHS method, See Figure 3.

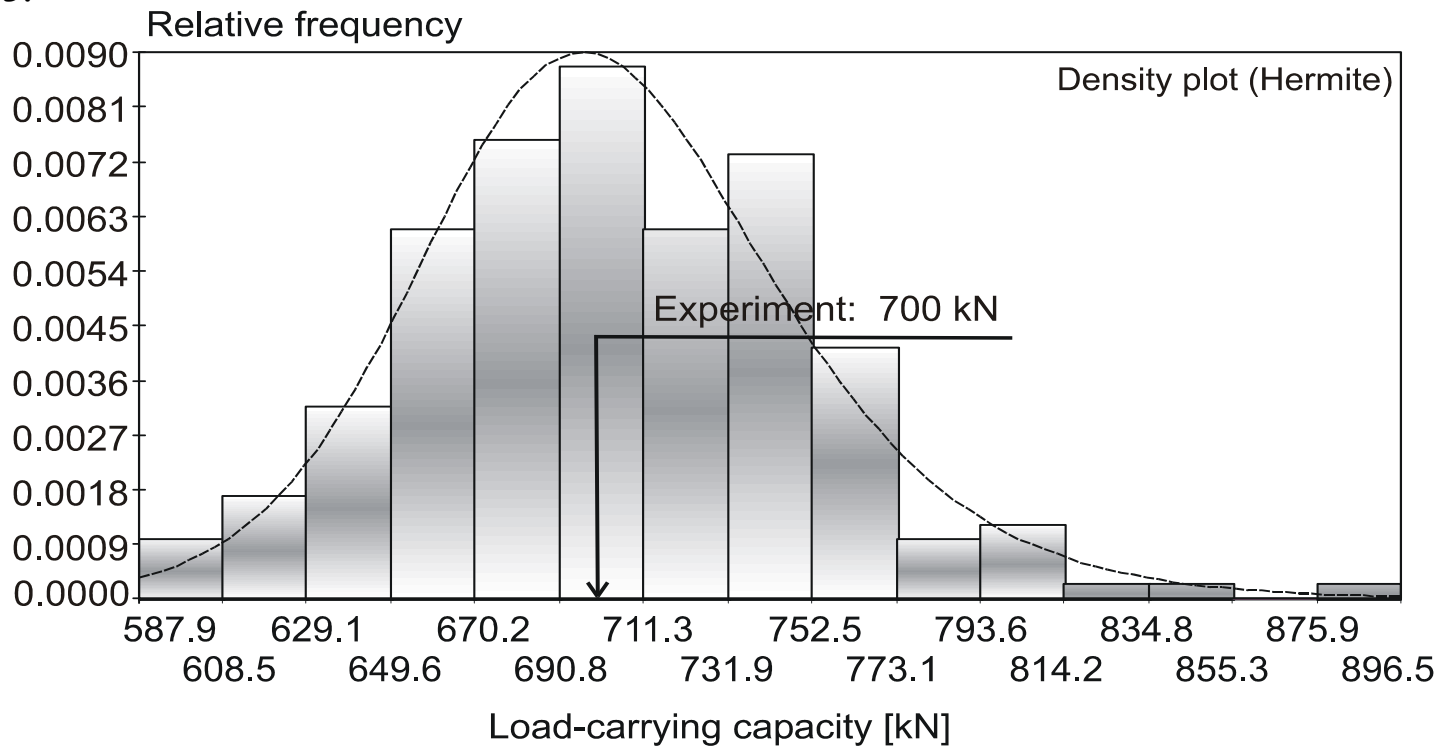

Figure 3. Distribution of Load-Carrying Capacity

\section{SENSITIVITY ANALYSIS RESULTS}

The stochastic sensitivity analysis enabled us to assess the relative sensitivity of random variability of the phenomenon studied to the random variability of individual input quantities. Figure 4 gives the results of an analysis of the sensitivity of the load-bearing capacity to initial imperfections. As long as the value of the correlation coefficient increases, the load-carrying capacity increases when also the value of the input quantity grows. A negative value of the coefficient heralds a negative effect of the quantity on the load-bearing capacity (e.g. quantity No I).

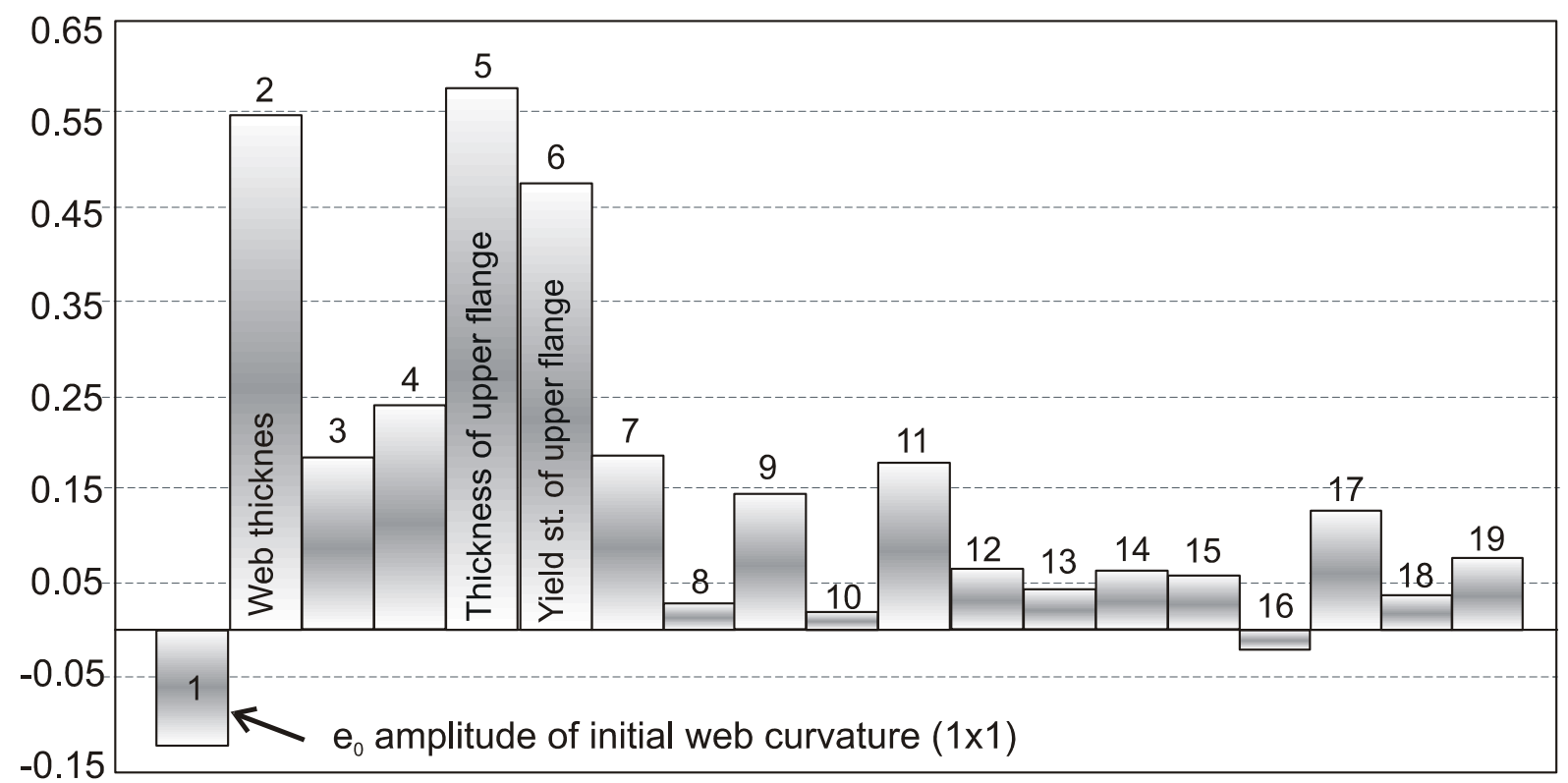

Figure 4. Sensitivity Analysis of the Load-Carrying Capacity 


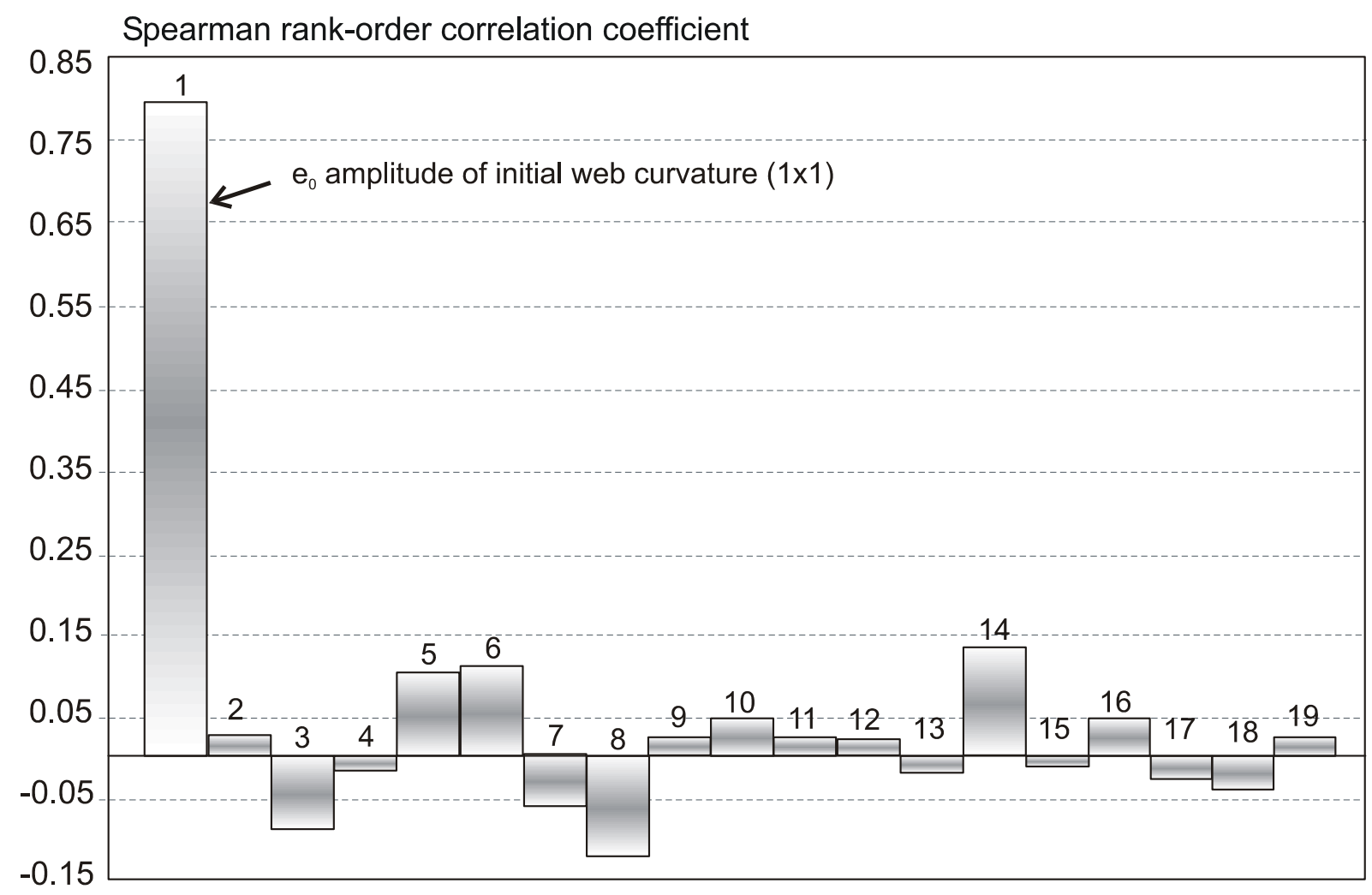

Figure 5. Sensitivity Analysis of the Bending Stress at Points A and B

\section{CONCLUSIONS}

It has been determined by the sensitivity analysis of static ultimate load carrying capacity that the girder upper flange thickness, web thickness and also upper flange yield strength influence the load-carrying capacity in the dominant way.

So long as the value of the quantities mentioned increases, the load-carrying capacity value increases, too. On the contrary, the variability influence of the web initial curvature $e_{0}$ on the girder load-carrying capacity is relatively low. The negative correlation coefficient value means that as long as the value of the amplitude of initial curvature $\mathrm{e}_{0}$ increases, the ultimate load-carrying capacity decreases.

The results of the authors' sensitivity analysis confirmed a great influence of the initial curvature of a slender web on the variability of bending stresses occurring at points $\mathrm{A}$ and $\mathrm{B}$, i.e. in the crack-prone areas of the web if the girder is subjected to repeated loading. On the contrary, if the same girder is under the action of a quasi-constant load, the influence of the initial out-of-flatness of the web on the ultimate strength of the girder (where the web is in the case studied exposed to combined shear and bending) is slight.

\section{ACKNOWLEDGEMENTS}

The presented research was supported by grants 103/07/1067 of GACR and IAA201720901 of AVCR and by research project Reg. No. MSM 0021630519. 


\section{REFERENCES}

[1] Kala, Z., "Fuzzy Probability Analysis of the Fatigue Resistance of Steel Structural Members under Bending", International Journal of Civil Engineering and Management, Vol 14, Issue 1, 2008, pp.67-72, ISSN 1392-3730.

[2] Kala, Z., "Sensitivity Analysis of the Stability Problems of Thin-walled Structures“, Journal of Constructional Steel Research 61 (2005), pp.415-422, ISSN 0143-974X.

[3] Kala, Z., "Sensitivity Assessment of Steel Members under Compression", Engineering Structures (2008), doi:10.1016/j.engstruct.2008.04.001.

[4] Novák, D., Teplý, B. and Shiraishi, N., "Sensitivity Analysis of Structures - A Review", Proc. of The Fifth International Conference on Civil and Structural Engineering Computing, Edinburgh, 1993, pp.201-207.

[5] Novák, D., Teplý, B. and Keršner, Z., "The Role of Latin Hypercube Sampling Method in Reliability Engineering”, Proc. of ICOSSAR'97 - The 7th Int. Conf. on Structural Safety and Reliability, Kyoto/Rotterdam: Balkema, 1997, Vol. 1, pp.403-409.

[6] Saltelli, A., Ratto, M., Andress, T., Camplolongo, F., Cariboni, J., Gatelli, D., Saisana, M. and Tarantola, S., "Global Sensitivity Analysis Guiding the Worth of Scientific Models", New York: John Wiley and Sons, 2007.

[7] Kala, Z., Kala, J., Škaloud, M. and Teplý, B., "Sensitivity Analysis of the Effect of Initial Imperfections on the (i) Ultimate Load and (ii) Fatigue Behaviour of Steel Plate Girders", International Journal of Civil Engineering and Management, Vol XI, No 2, 2005, pp.99-107, ISSN 1392-3730.

[8] Kala, Z., "Sensitivity Analysis of Carrying Capacity of Steel Plane Frames to Imperfections", In Proc. of Int. Conf. of Numerical Analysis and Applied Mathematics, Psalidi (Greece), 2008, pp.298-301, ISBN 978-0-7354-0576-9, ISSN 0094-243X.

[9] Mang, H. A., Jia, X., Hoefinger., G. "Hilltop Buckling as the Alfa and Omega in Sensitivity Analysis of the Initial Postbuckling Behavior of elastic structures", International Journal of Civil Engineering and Management, Volume 15, Number 1, 2009, p. 35-46, ISSN 1392-3730.

[10] Juozapaitis, A., Norkus, A., Vainiūnas P. "Shape Stabilization of Steel Suspension Bridge“, The Baltic Journal of Road and Bridge Engineering, Vilnius: Technika, 2008, Vol III, No 3, p. 137-144, ISSN 1822-427X.

[11] Melcher, J., "On some problems of analytical and probability approaches to structural design", In Proc. of the 3rd International Conference on Advances in Steel Structures, VOLS I \& II, Hong-Kong (China), 2002, pp. 1185-1192.

[12] Melcher, J., Kala, Z., Holický, M., Fajkus, M. and Rozlívka, L., "Design Characteristics of Structural Steels Based on Statistical Analysis of Metallurgical Products", Journal of Constructional Steel Research, 2004, Vol. 60, pp.795-808, ISSN 0143-974X.

[13] Guedes Soares, C., "Uncertainty Modelling in Plate Buckling", Journal Structural Safety, 1998, Vol. 5, pp. 17-34.

[14] Fukumoto, Y., Kajita, N. and Aoki, T., "Evaluation of Column Curves Based on Probabilistic Concept", In Proc. of International Conference on Stability, Prelim. Rep., Gakujutsu Bunken Fukyu - Kai Publ., 1976, Tokyo, pp. 1-37. 